\title{
Problems of sustainable implementation of the communication mechanism in the digital environment
}

\author{
Ekaterina Dolzhenkova ${ }^{1, *}$, Dmitri Mokhorov ${ }^{1}$, and Tatiana Baranova ${ }^{1}$ \\ ${ }^{1}$ Peter the Great St. Petersburg Polytechnic University, St. Petersburg, 195251, Russia
}

\begin{abstract}
Applying G. Lasswell's model of political communication to the modern development of the communication mechanism reveals new roles and opportunities for political elites. Political actors in modern society pursue the goal of effective management of the state (including civil society), as well as in preserving the legitimacy of the current government. The goal of the paper is to propose how the political elites can use the Internet space to achieve their own political goals to retain power, effectively manage the mass consciousness, give their own actions legitimacy and increase ratings.
\end{abstract}

\section{Introduction}

The features of the communication mechanism (Figure 1) aimed at civil society by the political elites of one state today are very contradictory. On the one hand, it is delivering important information, using digital technologies, including social networks, Internet space, radio, and television. On the other hand, it is collecting information about the preferences, views of a particular group of people. This information can then be used for various purposes of political elites, both external and internal, in particular, for identifying groups loyal and disloyal to this or that political party, political regime, etc.

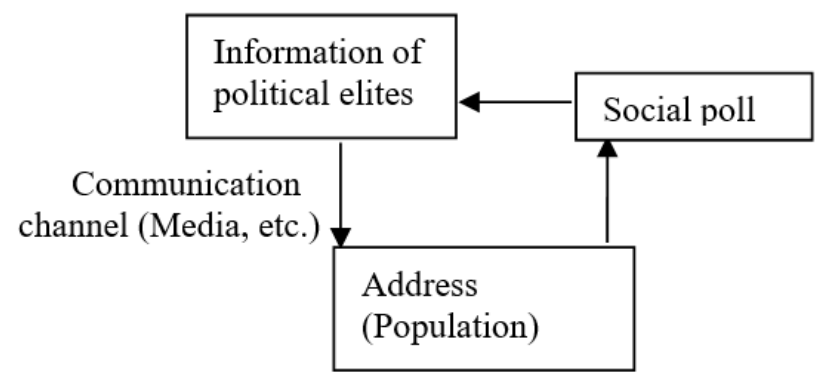

Fig. 1. Vertical communication mechanism.

Various social surveys in the public communication mechanism (vertical communication mechanism) are a response to certain government actions. Due to the fact

* Corresponding author: skinx@inbox.lv 
that currently information flows are concentrated not only through television and radio broadcasting, but also through various Internet platforms. It becomes difficult for the state law enforcement and political structures to control the information flows. And also, to conduct their own propaganda activities [1]. If the flows of information concentrated on TV and radio broadcasting are possible to control, by banning broadcasting on the territory of any state, or by creating and broadcasting the desired content. The information presented on social networks and other Internet platforms is quite difficult to control and block. In this case, there is a reason - social networks and Internet platforms are concentrated in the private sector. Yes, they are subject to the laws of the country where they are spread - they can be blocked by Internet providers, according to the regulation of the supervisory authorities. Or they are forced to remove information that, in the opinion of the supervisory authorities, is anti-social, anti-political, aggressive, controversial and offensive. It also enables creating pro-government content that would disseminate information needed by the ruling elite. But this content on the Internet encounters some obstacles, namely the distrust of users to the information presented by pro-government social groups or accounts. Since today there is a certain trend, which shows that social groups with oppositional views [2], or groups that are in a certain confrontation with another social group, whose leader is in confrontation with an alternative leader (for example), will use the information and will spread it through the Internet space, including contextual advertising, messengers, social networks, video and audio platforms. A similar situation was observed in the election campaign of D. Trump in the United States, where one of the reasons for the defeat of this candidate was the neglect of television broadcasting. The main campaign of D. Trump's headquarters was concentrated on the Internet. Where the main pre-election discussion was also held. However, outstandingly, J. Biden did not rule out the use of television broadcasting for his own election campaign to his benefit. The example of Great Britain, when campaigning for and against Brexit was carried out - where the ratio of voting shows that all possible methods and channels of communication were used. That is, the interests and preferences of all social groups (divided by nationality, age, and gender) in receiving and accepting information were taken into consideration. These examples clearly show the problem of democratic countries to use the communication mechanism in the digital environment. Which is to reach all social groups, and to know which communication channel is preferred by one or another social group.

The situation in other countries shows that it is necessary to take into consideration the level of trust in this or that communication channel of this or that group of people [3]. It is also necessary to take into consideration the level of trust of the population in progovernment structures, as well as in the channels that convey pro-government information. In this case, we are talking about television and radio broadcasting, as well as Internet channels. The ruling political elites need communication channels primarily to increase their own information flows, the purpose of which is to create a positive attitude among the population (both inside and outside the state (for example, among its own citizens living abroad) towards the national and international policies being carried out, to certain social and political projects, and to increase the level of trust and approval on the part of voters. Internet platforms allow pro-government structures and representatives of the authorities to communicate directly with social groups, as well as to obtain information about the level of approval and trust. Here, there could also be a problem of how to establish a communication channel on the Internet with all users. The opposition is unlikely to subscribe to a pro-government channel. Here it seems possible to use modern methods of managing the public opinion. Which include mechanisms for determining the users' interests, through which they are subsequently formed into Internet communities. And then there is the throwing in of information, communication (which involves Internet bots and Internet trolls, as well as real users), which form the necessary opinion. 
In this case, it can be argued that this mechanism can be used by both the opposition and pro-government structures [4]. The factor of strengthening the influence of the opposition will be due to the fact that the main audience on the Internet is oppositionminded users. Therefore, there is a problem for the power structures and current political power on the Internet - this field of activity, due to freedom, and initially formed as a space of free communication, including free expression of their own views and thoughts - has already formed according to its own laws and rules. And the pro-governmental agenda here has been alien and ineffective from the very beginning [5]. Government actions aimed at controlling and tightening measures and restricting the use of certain Internet platforms do not always lead to the expected result, due to the emergence of new methods of bypassing restrictions or joining closed messengers.

But is it enough to block information flows or to effectively manage them in order to influence social groups? Or to communicate effectively with civil society through television and radio broadcasting? If the goal is to legitimize a government action. Effective communication management in this case would be the result of the government action, which is the approval of government's actions by the society's majority, and, therefore, giving legitimacy to the government's actions.

\section{Methodology}

The research relies on general scientific methods, which are the method of analysis and the method of synthesis. As well as a special method - content analysis, which reveals different interpretations of political and social events in communication channels. The model of political communication of G. Lasswell is used [6]. Where the source of communication is the political elites, the channel of communication is the Internet space (messengers, social networks, audio and video platforms), the addressee of communication is users (social groups). The reaction of society (civil society), manifested in elections or in a protest movement, is taken as feedback. An important element of G. Lasswell's communication model. Lasswell's model of communication is supplemented by R. Braddock [7]. Namely, the conditions under which information dissemination (message) takes place and the goal (for what purpose this or that information is disseminated), i.e. what goals the source of information wants to achieve, interacting with the addressee in certain conditions, applying certain channels of communication.

\section{Results}

The legislative framework of the Russian Federation for regulating the work of the Internet [8] and controlling the actions of users in the network has been actively updated in the last few years [9]. The application of these measures was predictable, since the Internet space did not have a regulatory mechanism until recently. In the conditions of its increasing influence on the public opinion (public discourse). Those freedoms which the Internet gave to its users - it was an unregulated platform where people united according to their interests. This also gave the opposition an opportunity to attract supporters, which was reflected in the approval rating of the current political elite (a political leader). Consequently, the legitimacy of the government's actions was also at risk. Because of the unpopularity of the spread of pro-government views and the weak effect of propaganda on social networks and messengers, the pro-government structures needed to create a mechanism for controlling and regulating information on the network. But this is not the only reason for the increased control over online activity. There are dangers of the spread of terrorist and destructive 
information. Just as the situation with the Covid-19 pandemic showed, fake news can be threatening to the health of large social groups.

One of the functions of the state, namely its protective function, lies in the creation of regulatory mechanisms in the Internet space. The security agencies of the state have a duty to ensure safety of the civilian population from all kinds of threats. Threats to modern society are also concentrated in the Internet space.

But the current practice of applying restrictions in social networks (not only legislative acts, but also internal decisions of the management of IT companies) can be interpreted differently and be protective, on the one hand, and infringe on the freedom of speech rights, on the other. The events in the U.S., when Twitter blocked Donald Trump's profile page, can also be interpreted differently. On the one hand - it is an internal order of the Twitter management, calling on all users (including the President) to comply with the rules of the community and not to allow incitement to hatred, and to suspend calls for violence. On the other hand, the global company Twitter could thereby influence some of Trump's voters and supporters by restricting his access to one of the main channels of communication for political purposes.

The increased control on the Internet has recently manifested itself in the Republic of Belarus. In addition to the adoption of legislative acts that control the work of the Internet, as well as the activities of Internet users, methods of restricting access to the Intern et were often used. This tactic was used before. But it is also a clear example that social networks and messengers allow the civilian population to coordinate their actions within the framework of the protest movement quite effectively. Both the government's ability to control Internet traffic and the ability to interrupt Internet connections are important here.

Another problem for the security agencies is the possibility to create and coordinate a protest movement from outside the state territory. In this case, there is no possibility to prevent opposition activity by force (for example, detention of the coordinator, imprisonment or closure of the coordinating office with seizure of technical means). It is possible to prevent the spread of destructive information by closing access to opposition websites, platforms, etc. But due to the large number of messengers, which can be used to bypass state bans, this practice is not effective. Leaders of opposition movements, including their coordinators are often located outside the state territory. Another important point here is that the participants of protest movements may subsequently organize themselves under the influence of previously voiced ideas. In other words, there is a process in which a particular group independently chooses a "new" leader for the ongoing protest movement. And this process in the Internet space is developing rapidly, as it takes place online and covers a large audience, while also attracting new followers (users).

There is also a danger here for the ruling elite that opposition-minded citizens will seek to obtain new information about the protests in closed messengers. This also leads to an increase in the number of participants in the protest movement. This situation is also due to the actions of the government itself. As practice shows, state channels do not cover such actions during protests. The coverage of protest actions is often superficial. This encourages users to seek additional information on the Internet. It seems that this practice could be destructive. Because online platforms offer the possibility of online communication as well. This threat also arises from the possibility to unite people according to interests, which creates a sense of community and a sense of majority. And users who "came" to an alternative messenger can become new participants in the protest movement. The coordinators of the protest movements here also have the opportunity to effectively manage a large group of people (up to taking people "out on the street"). Thus, the state apparatus independently transfers the ability to control mass consciousness to the leaders of the protest movement, whose main platform was originally the Internet. 
China's experience clearly demonstrates the role of the Internet space [10]. Implementing a political program, the Chinese leadership assessed the role of the Internet in society in the first decade of the XXI century. Which now allows us to regard China as a major exporter of technology, standards, and ideas in the field of mass communications control and prevention of unrest. Chinese IT companies have created not only their own Internet network, but also their own, and therefore government-controlled, social networks (equivalents of Twitter, Instagram, etc.). This allows the ruling political party to create and apply mechanisms to control the behavior of the population in the Internet space. But information flows are also worth noting. Information flows can be controlled and edited by Chinese law enforcement agencies [11], i.e., not to allow offensive, controversial content and its distribution. Which, according to local experts, could harm public security or the political system. Thus, information in China is controlled by political elites. But the uniqueness of China's experience is not only in the control of information, but also in the control of the behavior of the population, as well as in the application of physical measures. Physical measures involve both checking user devices for anti-government (banned) information in, and creating the system of "Social Credit" [12]. That is, the Chinese government has created a unique system that not only prohibits, but also motivates the population to "exemplary behavior". In view of the fact that China is interested in exporting its own technology and also maintains diplomatic and economic relations with the countries of the post-Soviet region, which, as the recent events of the 2020s show, needs to modify the control over the behavior of Internet users. There is a possibility of the introduction of Chinese technology and the application of its experience in the countries of Central Asia and the CIS.

\section{Discussion}

Equations should be centred and should be numbered with the number on the right-hand side. Taking into consideration the conditions under which protest movements take place, it seems that state structures need to reconsider the practice of covering (not covering) protests in television and radio broadcasts. This will reduce the number of new users joining the "protest messengers". The purpose of which, from the beginning, was to obtain alternative (by conviction, "truthful") information. Or to apply the experience of China, which will allow controlling the flow of information and the behavior of the population.

Also, the third way is possible - reorganization of the behavior of political elites on the Internet. Namely, (here the experience of interaction of representatives of the authorities in the United States serves as a clear example) on their own, i.e. by giving "personal characteristics" to their profile on social networks, to maintain their own Internet pages. This practice is supposed to convey a sense of interpersonal (more intimate) communication between representatives of the political elite and the civilian population. This also plays a role in the feeling of closeness and the emergence of the feeling that a representative of power is close to the people and understands the needs and interests of the majority of civilians. A certain commonality emerges.

This practice can allow you to bypass fake news and various controversial throw-ins, because there is a legitimate primary source of information, which (by definition) can be trusted. It is also an opportunity to communicate directly with voters. Which will allow attracting the electorate and maintaining high approval ratings of the ruling elite. In other words, it is a channel of communication, where the leader (their team) independently, unilaterally creates conditions, conveys information to certain users, and receives feedback. But since it is a mechanism of communication, it is possible to regulate this communication, achieving the expected result. Here, it is necessary to distinguish between social pages which rebroadcast events of political life and provide some quotes and videos 
of the activities of political leaders from first-person statements (messages). It is advisable to pretend, if it is not possible to maintain a social page on their own, that it is the political leader who maintains it, and it is him who publishes this or that post. This will also allow not only the opposition, but also the acting authorities to come and win their niche in the Internet.

\section{Conclusion}

Thus, with the increase in communication channels, political parties and their representatives need to adapt to public demand for information, otherwise the place of "chief informer" on the Internet turn to the opposition. This can be done in three ways (which take place in some regions):

- tightening control over information and behavior in the Internet space through expanding the legal framework;

- tightening control over information and behavior on the Internet by creating its own Internet network, monopolizing the social networking market, and tightening all-round control measures with the use of physical force and manipulation practices;

- using social media to be able to communicate directly with users, i.e., with civilians.

\section{References}

1. E. Dolzhenkova, V.G. Bakalov, Bulletin of L.N. Gumilyov Eurasian National University 1 (2020)

2. V.P. Kolomiets, Sotsiologicheskie issledovaniya 6 (2017)

3. Y. Artamonova, S. Volodenkov, Sotsiologicheskie issledovaniya 1 (2021)

4. S. Volodenkov, S. Fedorchenko, Sotsiologicheskie issledovaniya 11 (2018)

5. E. Shestopal, A. Selezneva, Sotsiologicheskie issledovaniya 10 (2018)

6. A.L. Alyushin, Polis 5 (2006)

7. L.R. Tuhvatulina, Tomsk State Pedagogical University Bulletin 7 (2006)

8. A. Prokopenko, Russia's Sovereign Internet Law Will Kill Innovation (Carnegie Moscow Center) https://carnegie.ru/commentary/78946

9. Y. Dorovskaya, D. Mokhorov, V. Snetkov, K. Semenova, A. Tebryaev, IOP Conferences Series: Materials Science and Engineering 940(1) (2020)

10. L. Kovachich, Bolshoy brat pod kozhey: kak Kitay vivodit slezhku na geneticheskiy uroveny (Carnegie Moscow Center) https://carnegie.ru/commentary/75492

11. T. Umarov, In Belarus, China Is Neither at Odds With Russia nor Wedded to Lukashenko (Carnegie Moscow Center) https://carnegie.ru/commentary/82662

12. L. Kovachich, Bolshoy brat 2.0. Kak Kitay stroit cifrovuyu diktaturu (Carnegie Moscow Center) https://carnegie.ru/commentary/71546 